\title{
A Successful Treatment of Ostraceous Psoriasis Associated with Psoriatic Arthritis in Children: A Case Report
}

This article was published in the following Dove Press journal: Psoriasis: Targets and Therapy

\author{
Rasmia Rowawi \\ Gilang Dwipangestu \\ Oki Suwarsa \\ Hartati Purbo Dharmadji \\ Endang Sutedja \\ Miranti Pangastuti (D) \\ Hendra Gunawan (D) \\ Department of Dermatology and \\ Venereology, Faculty of Medicine, \\ Universitas Padjadjaran-Dr. Hasan Sadikin \\ Hospital, Bandung 40I6I, Indonesia
}

Correspondence: Hendra Gunawan Department of Dermatology and Venereology, Faculty of Medicine, Universitas Padjadjaran-Dr. Hasan Sadikin General Hospital, Jl.Pasteur No. 38, Bandung, West Java 4016I, Indonesia Tel/Fax +62 222032426 ext. 3449 Email h.gunawan2016@unpad.ac.id

\begin{abstract}
Psoriasis may manifest as severe hyperkeratotic lesions resembling an oyster shell called ostraceous psoriasis (OP). This type of psoriasis is extremely rare and is often associated with psoriatic arthritis (PA). Cases of OP associated with PA in children have never been reported before. We reported a 9-year-old girl with hyperkeratotic lesions resembling an oyster shell all over the body accompanied with swelling on joints of both fingers, knee joints, and ankle. Histopathological examination supported the diagnosis of OP. The diagnosis of PA was established according to the Classification Criteria for Psoriatic Arthritis (CASPAR). Significant improvements of the skin lesions and joints involved were observed within 44 days after the beginning of treatment with cyclosporine and a combination of high potent topical steroid with emollient. OP associated with PA is uncommonly seen in children. High potent corticosteroid combined with emollient showed good result in skin improvement with low side effects. In addition, cyclosporine can be a good choice of systemic therapy for OP with PA in children.
\end{abstract}

Keywords: children, corticosteroid, cyclosporine, ostraceous psoriasis, psoriatic arthritis

\section{Introduction}

Psoriasis is a chronic inflammatory disease of the skin due to genetic factors. It can occur at any age but is rarely found in children less than 10 years old. Ostraceous psoriasis (OP) is one type of psoriasis with a typical lesion form of a circular hyperkeratotic lesion resembling an oyster shell. ${ }^{1,2}$ This variety was extremely rare, with few reports in the literature, and is often associated with psoriatic arthritis (PA). ${ }^{2}$

Psoriatic arthritis is a chronic inflammatory disease of the joint related to psoriasis. Symptoms include pain, stiff joint, swelling, tenderness, and limited joint movements. ${ }^{3}$ Classification Criteria for Psoriatic Arthritis (CASPAR) is a diagnostic criteria with high sensitivity and specificity to establish diagnosis of PA. ${ }^{4,5}$ We aimed to present a rare case of OP associated with PA in a child treated with cyclosporine and combination of high potent topical corticosteroid with emollient.

\section{Ethical Approval}

This study was conducted in compliance with the Declaration of Helsinki, Good Clinical Practices, and local regulatory requirements. Ethics committee approval 
was obtained. The Research Ethical Committees of the Dr. Hasan Sadikin Hospital Bandung approved the study with approval number LB.02.01/X.6.5/248/2020.

\section{Consent for Publication}

The patient's parents have signed informed assent forms. They also signed forms giving their consent for the use of case details and images for publication and for scientific purposes.

\section{Case Presentation}

A 6-year-old girl presented with hyperkeratotic lesions resembling an oyster shell over the body with occasional itch. This condition was accompanied with swelling and pain on joints of both sides of the fingers, knee, and ankle. Twenty-five days before admission, the patient had suffered from upper respiratory tract infection. Nine days later, the first skin lesions appeared on the abdominal region in the form of erythematous macules. Eight days before admission, the skin lesions enlarged, increased in numbers, and appeared on the scalp, face, chest, back, and arms with thin scales on the surface of skin lesions. The patient was taken to primary health care, and received topical corticosteroid. However, there was no clinical improvement, therefore the patient was referred to our hospital. The patient weighed $9.2 \mathrm{~kg}$. Physical examination showed swelling, pain, and rigidity of both fingers, knees, and ankles, with dactylitis on the second, third, and fourth fingers of both hands (Figure 1). Pitting nail, onycholysis, and oily spot were found of the fingers on both hands.
Erythematous plaques with hyperkeratotic scales resembling an oyster shell (Figure 2) were observed almost all over the body, with involvement of $8 \%$ of total body surface area. Laboratory examination showed anemia and negative rheumatoid factor. Histopathological examination of hyperkeratotic lesion from the body revealed psoriasiform reaction with hyperkeratosis, parakeratosis, and Munro's microabscess (Figure 3) that supported the diagnosis of OP. Diagnosis of PA in this case was established based on CASPAR criteria which had met five (at least 3 points) of the total eight points, including current psoriasis (2 points), current dactylitis ( 1 point), negative rheumatoid factor (1 point), and typical psoriatic nail dystrophy, including onycholysis, pitting, and hyperkeratosis (1 point). Radiography examination was not performed due to the patient refusing examination. The patient was treated with $0.05 \%$ clobetasol propionate cream combined with emollient lotion (ratio 1:3) for thick plaques and scales, $25 \mathrm{mg}$ cyclosporine daily ( $2.7 \mathrm{mg} / \mathrm{kg}$ bodyweight per day), and $5 \mathrm{mg}$ meloxicam daily. Clinical improvement was started on day 28 of observation and significant improvements on the joints involved and skin lesions occurred on day 44 of observation, with reduced pain and swelling on the joints involved as well as resolution of skin lesions (Figure 4). Topical clobetasol propionate was stopped and the patient only received emollient lotion. We planned the initial dose of cyclosporine would be continued for 2 months then taper off. Unfortunately, the patient did not come for further treatment and loss to follow-up.
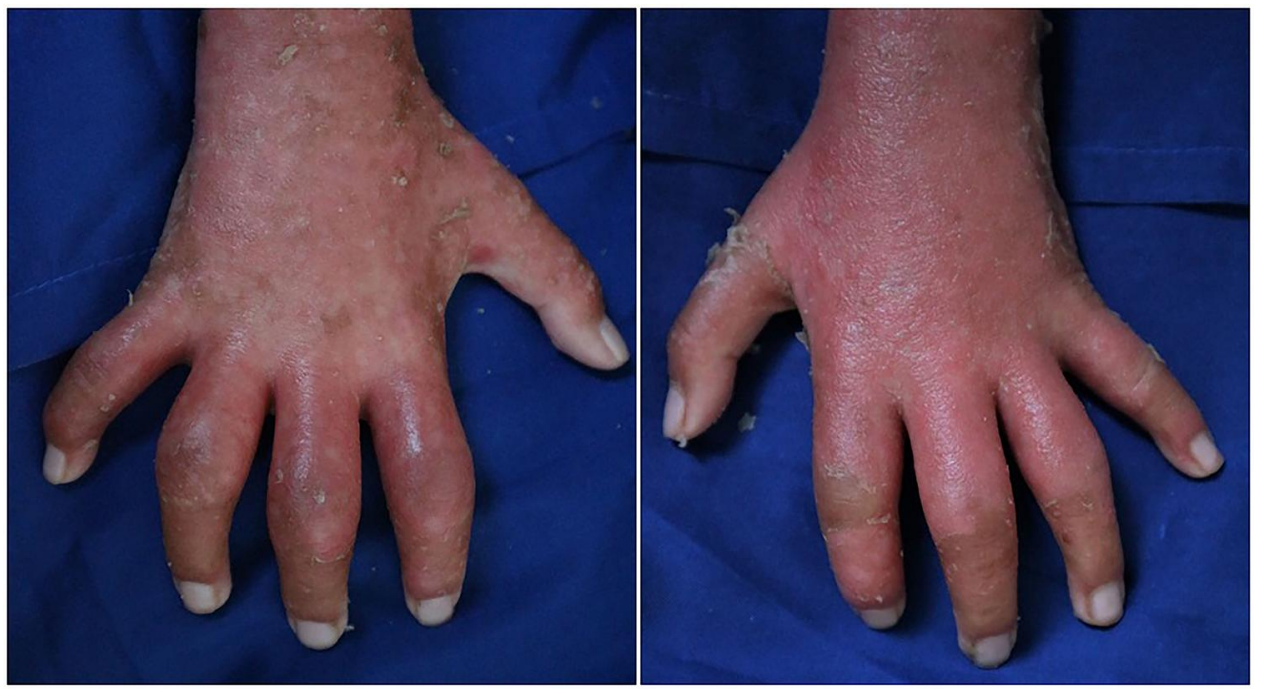

Figure I Clinical manifestation of PA. Dactylitis on all fingers of the right and left hands. Abbreviation: PA, psoriasis arthritis.. 


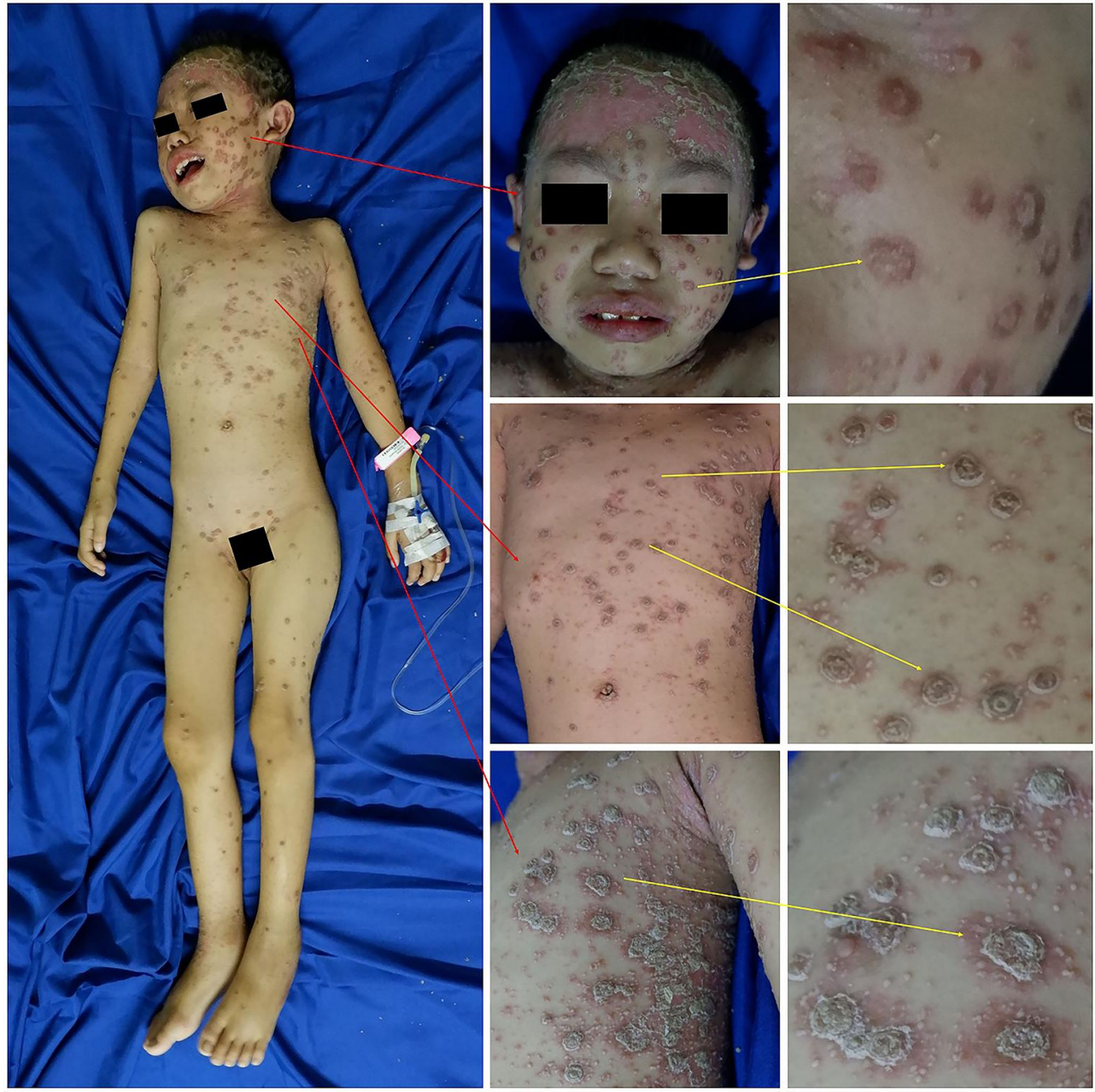

Figure 2 Clinical manifestation of OP. Erythematous plaques with hyperkeratotic scales resembling an oyster shell. Abbreviation: OP, ostraceous psoriasis.

\section{Discussion}

Psoriasis is a chronic inflammatory disease of the skin that is rarely found at the age of less than 10 years. ${ }^{1}$ Upper respiratory tract infection has been presumed to be a precipitating factor to the onset of psoriasis. Almost 50\% cases of upper respiratory tract infections are caused by streptococcal species. The immune cell of $\mathrm{T}$ helper $(\mathrm{Th})$ 17 and its related cytokine network are important in mucosal defense, being very effective against extracellular microbes. Streptococcal has the ability as a superantigen and can increase the activity of Th17 cell which has an important role in the pathogenesis of psoriasis. ${ }^{6}$

Psoriatic skin lesions may manifest as intensely hyperkeratotic lesions. It is further classified as ostraceous, rupioid, and elephantine psoriasis. ${ }^{1}$ Lesions with firmly adhered thick scales, hyperkeratotic concave lesion, and resemblance of an oyster shell are typical features of ostraceous psoriasis. ${ }^{1,2}$ Rupioid psoriasis refers to lesions in the shape of a cone or limpet, while elephantine psoriasis is an uncommon form characterized by thickly scaling, large plaques, usually on the lower extremities. ${ }^{1}$ These varieties are extremely rare, with few reports in the literature. ${ }^{2}$ The patient described in this case presented with generalized erythematous plaques with hyperkeratotic scales resembling an oyster shell that supported the diagnosis of OP.

Histopathological features of OP share some similarities with psoriasis vulgaris. These similarities include parakeratosis with neutrophil infiltration in the stratum corneum, Munro's microabscess, epidermal hyperplasia with elongation of rete ridges, hypogranulosis, and dilatation of blood vessels in the dermis. ${ }^{7}$ The histopathological examination result of this patient supported the diagnosis of OP.

Ostraceous psoriasis is resistant to topical treatments and is associated with $\mathrm{PA}^{2}$ The symptom of PA appeared as pain, stiff joint, swelling, tenderness, and limited joint movement. The CASPAR criteria consists 


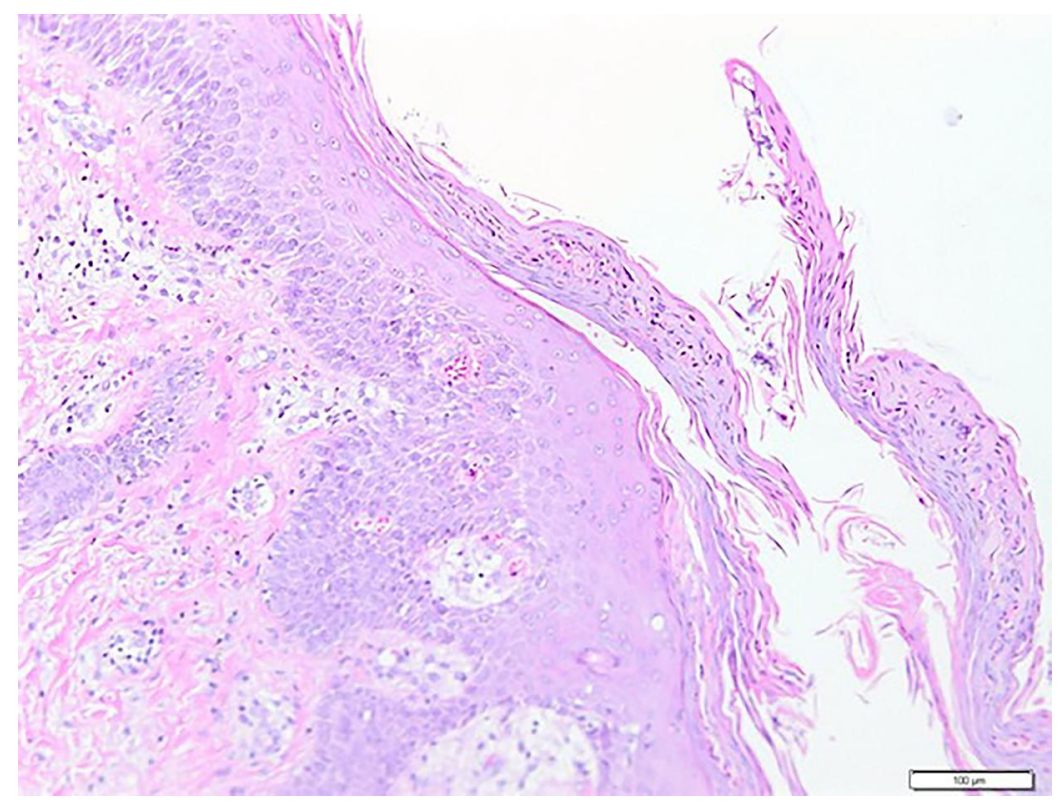

Figure 3 Histopathological findings (H\&E staining 100x). Histopathological results revealed hyperkeratosis, parakeratosis, and Munro's microabscess.

of established inflammatory articular disease with at least 3 points from the following features; current psoriasis ( 2 points), personal history of psoriasis (1 point), family history of psoriasis (1 point), current dactylitis or history of dactylitis recorded by a rheumatologist (1 point), juxta-articular new bone formation (1 point), negative rheumatoid factor (1 point), typical psoriatic nail dystrophy including onycholysis, pitting, and hyperkeratosis (1 point). ${ }^{4,5}$ Diagnosis of PA in this case was established based on the presence of five points symptom based on CASPAR criteria in the forms of current psoriasis (2 points), current dactylitis (1 points), negative rheumatoid factor (1 points), and typical psoriatic nail dystrophy including onycholysis, pitting, and hyperkeratosis (1 points).

Determination of therapy in psoriasis is selected based on the degree of severity represented by the body surface area (BSA). BSA less than 5\% included in mild-degree psoriasis and topical treatment is required. BSA with a score $5-10 \%$ included in moderate-to-severe psoriasis and requires topical and systemic treatment. Meanwhile, BSA with a score more than $10 \%$ included in severe degree of psoriasis and only need a systemic treatment. ${ }^{8}$ In this case, the patient's BSA was $8 \%$ included in moderate-to-severe psoriasis and requiring topical and systemic treatment.

Corticosteroids are the first line topical treatment for psoriasis in all age groups. ${ }^{9}$ These drugs are suitable for treating childhood psoriasis older than 2 months of age. ${ }^{10}$ Psoriasis has a moderate response to topical corticosteroid, thus requiring moderate-to-high potent topical corticosteroid. ${ }^{1}$ The use of high potent corticosteroid in children should not be used for more than 2 weeks regarding the side-effects. ${ }^{10}$ To reduce the side-effects of high potent topical corticosteroids, combination with emollients is one of the strategies in topical corticosteroids treatment. ${ }^{11}$ The patient in this case was treated with $0.05 \%$ clobetasol propionate cream combined with emollient lotion (ratio 1:3) for thick plaques and scales without showing any side-effects.

Cyclosporine is the first-line therapy for moderate-tosevere psoriasis, pustules psoriasis, erythroderma, and PA. ${ }^{12}$ Initial dose of cyclosporine therapy is $2.5 \mathrm{mg} / \mathrm{kg}$ bodyweight per day and can be increased until a maximum dose $5 \mathrm{mg} / \mathrm{kg}$ bodyweight per day. Absolute contraindications of cyclosporine are renal disease, uncontrolled hypertension, and severe infections. ${ }^{1,13}$ In this patient, no contraindication was found from history taking, physical examination, and laboratory examination. Therefore, the patient was able to be treated with received cyclosporine. In this patient, significant improvements on the skin lesions and joints involved occurred on day 44 of observation, with resolution of skin lesions as well as reduced pain and swelling on the joints involved.

The dose of cyclosporine can be reduced by $0.5 \mathrm{mg} / \mathrm{kg}$ / day every month, if the remission of signs and symptoms 


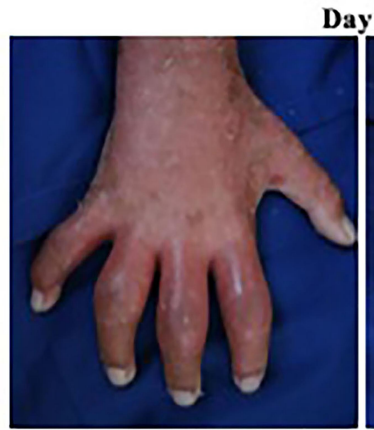

Day 1

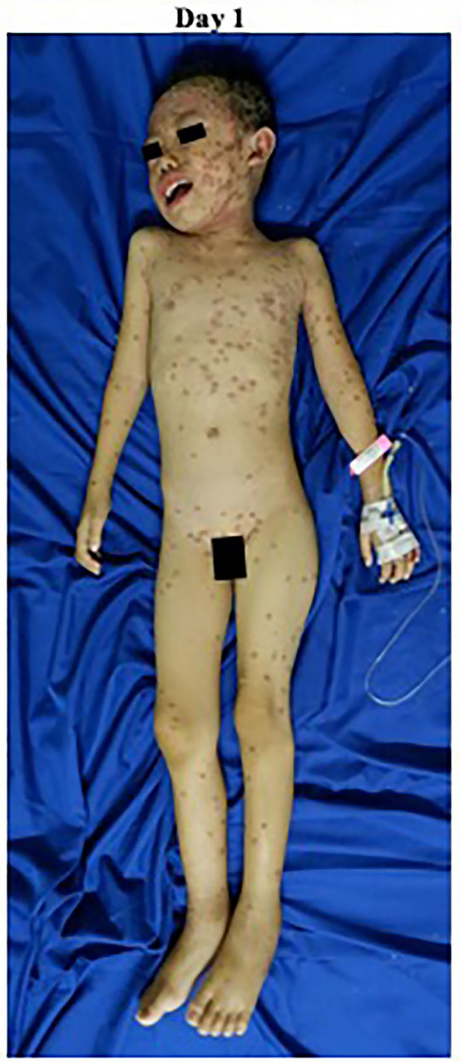

ay 1

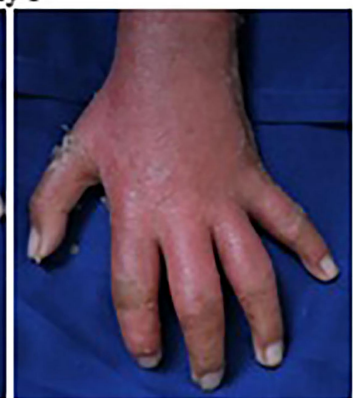

Day 44

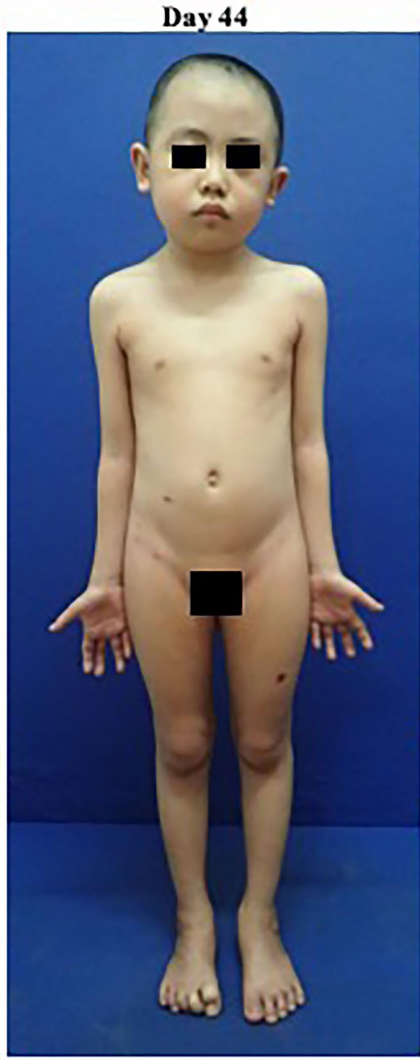

Day 44

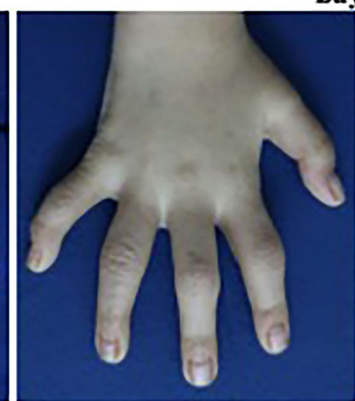

Day 1
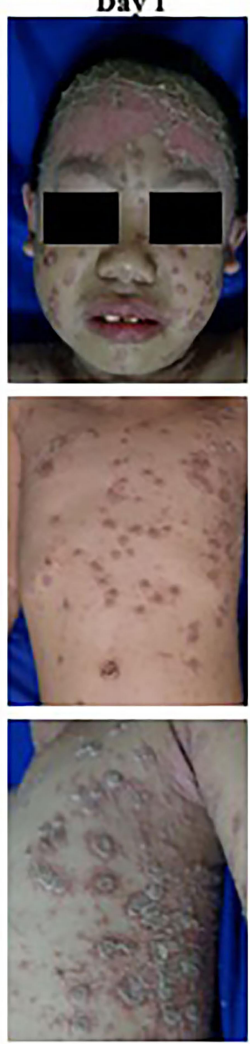

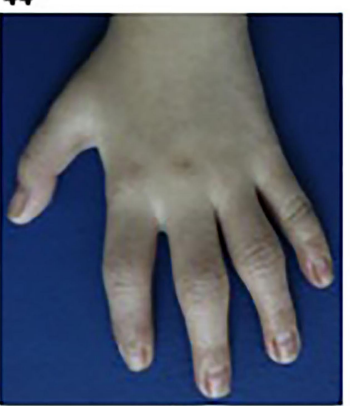

Day 44
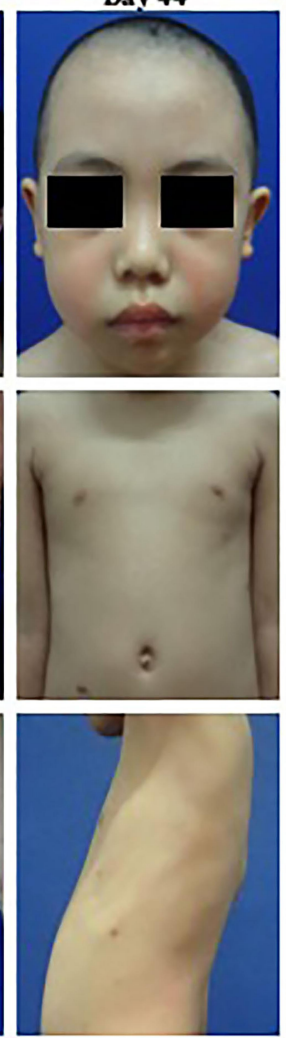

Figure 4 Clinical manifestation of OP and PA before and after treatment. Significant improvements on joints involved and the skin lesions occurred on day 44 of observation, with reduced pain and swelling on the joints involved as well as resolution of skin lesions.

Abbreviation: OP, ostraceous psoriasis; PA, psoriasis arthritis.

has been achieved. ${ }^{12}$ In general, treatment duration of cyclosporine should not exceed 12 months, and close monitoring of renal function is mandatory. Therefore, laboratory and blood pressure monitoring before and during treatment is essential. ${ }^{14}$ Safety of cyclosporine for long-term treatment is uncertain. ${ }^{15}$ If long-term therapy is required and the use of cyclosporine exceeds the limit, other systemic drugs should be considered such as methotrexate. ${ }^{10}$ In this case, we planned the initial dose of cyclosporine would be continued for 2 months and then taper off. Unfortunately, the patient did not come for further treatment and loss to follow-up.
Retinoid is a systemic treatment suitable for children with pustular psoriasis, erythrodermic or severe plaque psoriasis with mechanism of action as modulator of the keratinocytes proliferation and differentiation. ${ }^{10,14}$ Meanwhile, etanercept is one of the biologic drugs recommended for the treatment of childhood psoriasis. ${ }^{10}$ Unfortunately, these two drugs are not available in our country.

\section{Conclusion}

High potent corticosteroids combined with emollients showed a good result in skin improvement with low 
side-effects. In addition, cyclosporine can be a good choice of systemic therapy for OP with PA in children.

\section{Abbreviations}

CASPAR, Classification Criteria for Psoriatic Arthritis; OP, ostraceous psoriasis; PA, psoriasis arthritis.

\section{Acknowledgments}

The authors would like to thank all staff of the Dermatology and Venereology Department, Faculty of Medicine Universitas Padjadjaran - Hasan Sadikin General Hospital Bandung.

\section{Author Contributions}

All authors made a significant contribution to the work reported, whether that is in the conception, study design, execution, acquisition of data, analysis and interpretation, or in all these areas; took part in drafting, revising, or critically reviewing the article; gave final approval of the version to be published; have agreed on the journal to which the article has been submitted; and agree to be accountable for all aspects of the work.

\section{Funding}

The authors declared that this study has received no financial support.

\section{Disclosure}

The authors report no conflicts of interest in this work.

\section{References}

1. Gudjonsson JE, Elder JT. Psoriasis. In: Goldsmith LA, Katz SI, Gilchrest BA, Paller AS, Leffell DJ, Wolff K, editors. Fitzpatrick's Dermatology in General Medicine 8th Edition. New York: McGrawHill; 2012:pp. 197-231.
2. Sherlock J, Portugal FM, Mota LDS, Fakhouri R, Silva SFD. Case for diagnosis. Ostraceous psoriasis: a case report. An Bras Dermatol. 2014;89(5):841-842. doi:10.1590/abd1806-4841.20143195

3. Gladman DD, Chandran V. Psoriatic Arthritis. In: Goldsmith LA, Katz SI, Gilchrest BA, Paller AS, Leffell DJ, Wolff K, editors. Fitzpatrick's Dermatology in General Medicine 8th Edition. New York: McGraw-Hill; 2012:pp. 232-42.

4. Rithclin CT, Colbert RA, Gladman DD. Psoriatic arthritis. $N$ Engl J Med. 2017;376(21):2095-2096.

5. Gottlieb A, Korman NJ, Gordon KB, et al. Guidelines of care for the management of psoriasis and psoriatic arthritis: section 2. Psoriatic arthritis: overview and guidelines of care for treatment with an emphasis on the biologics. J Am Acad Dermatol. 2008;58(5):851864. doi:10.1016/j.jaad.2008.02.040

6. McFadden JP, Baker BS, Powles AV, Fry L. Psoriasis and streptococci: the natural selection of psoriasis revisited. $\mathrm{Br} J$ Dermatol. 2009;160(5):929-937.

7. Weedon D. The psoriasiform reaction pattern. In: Weedon D, editor. Weedom's Skin Pathology 3th Edition. London: Churcil Livingstone Elsevier; 2010:pp. 72-91.

8. Kupetsky EA, Keller M. Psoriasis vulgaris: an evidence-based guide for primary care. J Am Board Fam Med. 2013;26(6):787-801. doi:10.3122/jabfm.2013.06.130055

9. Cordoro KM. Topical therapy for the management of childhood psoriasis: part I. Skin Therapy Lett. 2008;13(3):1-3.

10. Thomas J, Parimalam K. Treating pediatric plaque psoriasis: challenges and solutions. Pediatric Health Med Therapeutics. 2016;7:2538. doi:10.2147/PHMT.S75834

11. Bhutani T, Kamangar F, Cordoro KM. Management of pediatric psoriasis. Pediatr Ann. 2012;41(1):e1-7. doi:10.3928/0090448120111209-08

12. Hogan PA, Langley RGB. Papulosquamous disease. In: Schachner LA, Hansen CR, editors. Pediatric Dermatology. New York: Elsevier; 2011:pp. 901-51.

13. Lebwohl M, Ellis C, Gottlieb A, et al. Cyclosporine consensus conference: with emphasis on the treatment of psoriasis. $J \mathrm{Am}$ Acad Dermatol. 1998;39(3):464-475. doi:10.1016/S0190-9622(98) 70325-1

14. Napolitano M, Megna M, Balato A, et al. Systemic treatment of pediatric psoriasis: a review. Dermatology Therapy. 2016;6(2):125142. doi:10.1007/s13555-016-0117-6

15. Ellis CN, Fradin MS, Messana JM, et al. Cyclosporine for plaquetype psoriasis. Results of a multidose, double-blind trial. $N$ Engl $J$ Med. 1991;324(5):277-284. doi:10.1056/NEJM199101313240501
Psoriasis: Targets and Therapy

\section{Publish your work in this journal}

Psoriasis: Targets and Therapy is international, peer-reviewed, open access journal focusing on psoriasis, nail psoriasis, psoriatic arthritis and related conditions, identification of therapeutic targets and the optimal use of integrated treatment interventions to achieve improved outcomes and quality of life. Visit http://www.dovepress. com/testimonials.php to read real quotes from published authors. 